Comprehensive Models of Autism Spectrum Disorder Treatment 

Raymond G. Romanczyk • John McEachin Editors

\section{Comprehensive Models of Autism Spectrum Disorder Treatment}

Points of Divergence and Convergence

鱼 Springer 


\author{
Editors \\ Raymond G. Romanczyk \\ Institute of Child Development \\ Binghamton University \\ Binghamton, NY, USA
}

\author{
John McEachin \\ Autism Partnership \\ Seal Beach, CA, USA
}

ISBN 978-3-319-40903-0

ISBN 978-3-319-40904-7 (eBook)

DOI 10.1007/978-3-319-40904-7

Library of Congress Control Number: 2016948210

(C) Springer International Publishing Switzerland 2016

This work is subject to copyright. All rights are reserved by the Publisher, whether the whole or part of the material is concerned, specifically the rights of translation, reprinting, reuse of illustrations, recitation, broadcasting, reproduction on microfilms or in any other physical way, and transmission or information storage and retrieval, electronic adaptation, computer software, or by similar or dissimilar methodology now known or hereafter developed.

The use of general descriptive names, registered names, trademarks, service marks, etc. in this publication does not imply, even in the absence of a specific statement, that such names are exempt from the relevant protective laws and regulations and therefore free for general use.

The publisher, the authors and the editors are safe to assume that the advice and information in this book are believed to be true and accurate at the date of publication. Neither the publisher nor the authors or the editors give a warranty, express or implied, with respect to the material contained herein or for any errors or omissions that may have been made.

Printed on acid-free paper

This Springer imprint is published by Springer Nature

The registered company is Springer International Publishing AG Switzerland 


\section{Preface}

This book represents the proceedings of a conference held in January 2015 entitled: Evidence and Rationales for Comprehensive Models of Autism Spectrum Disorder Treatment: Divergence and Convergence. The conference was a collaboration between the Council on Autism Services and the Autism Partnership, conceived to move forward a critical dialog on the state of autism services. The project spanned 2 years from inception to planning to execution. The conference was very successful and filled to capacity. Thus this was the motivation to bring the proceedings to those who were not fortunate enough to attend.

We have kept the language and tone of the proceedings faithful to the actual presentations. Some adjustment was required because video examples were used in some cases. We also have inserted references into the text although these were not all part of the actual presentations. We did this to allow the reader further resources as a substitute for the conversations that took place at the conference when attendees wished further information.

Of note, the presenters all shared their knowledge gratis - there were no speaker stipends or honoraria. They spoke because of their commitment to the filed of autism spectrum disorder which in turn allowed us to produce a conference that did not present a financial barrier to those many individuals who wanted to attend. The detailed, innovative, evidence-based, and collegial presentations and discussions presented here represent a unique and much needed addition to the professional and consumer literature.

I wish to thank all of my colleagues at the Council on Autism Services (recently had a name change to Council of Autism Service Providers-CASP) and the Autism Partnership for supporting this effort, our speakers who gave so graciously of their time, knowledge, and expertise, and I also want to thank Dr. Rachel Cavalari who worked tirelessly with me to make the conference and the proceedings come to fruition. 



\section{Acknowledgments}

We thank Jennifer Bertolo for her excellent assistance in the initial transcript editing and the integration of the presenters' graphics with the conference transcripts. 



\section{Contents}

1 Prologue and Introduction ................................................................ Raymond G. Romanczyk

2 “The Lovaas Model: Love It or Hate It, But First Understand It"...... 7 Ronald Leaf and John McEachin

3 Early Start Denver Model Sally Rogers

4 The New England Center for Children: Applied Behavior Analysis for Treating All Levels of ASD Severity William H. Ahearn

5 The Value of a Behavioral Analysis of Language for Autism Treatment

Mark L. Sundberg

6 Panel Discussion

Raymond G. Romanczyk

7 Commentary on Commonalities and Divergence John McEachin

8 Audience Questions and Closing Comments Raymond G. Romanczyk

9 Epilogue: ASD Treatment Implementation-Parameters and Considerations

Rachel N.S. Cavalari and Jennifer M. Gillis

Index 



\section{Contributors}

William H. Ahearn, Ph.D., BCBA-D The New England Center for Children, Southborough, MA, USA

Rachel N.S. Cavalari, Ph.D., BCBA-D Institute for Child Development, Binghamton University, Binghamton, NY, USA

Jennifer M. Gillis, Ph.D., BCBA-D Binghamton University, Binghamton, NY, USA

Ronald Leaf, Ph.D. Autism Partnership, Seal Beach, CA, USA

Sally Rogers, Ph.D. UC Davis, Mind Institute, Davis, CA, USA

Mark L. Sundberg, Ph.D., BCBA-D Behavior Analysis Center for Autism, Fishers, IN, USA 



\section{About the Contributors}

William H. Ahearn, Ph.D., BCBA-D , joined The New England Center for Children in August 1996 and currently serves at NECC as the Director of Research. He is also Adjunct Faculty in Western New England University's doctoral and masters programs. He was the 2009 American Psychological Association-Division 25 awardee for Enduring Contributions to Applied Behavioral Research. He has published extensively on behavior analytic interventions for treating problem behavior and teaching social and communicative behavior for individuals with autism, related disabilities, and typically developing children. Dr. Ahearn is Past President of the Association of Professional Behavior Analysts and the Berkshire Association for Behavior Analysis and Therapy, has been involved in establishing regulatory practices for behavior analysts, and currently serves on the Massachusetts Board that licenses behavior analysts. He also serves as Editor-in-Chief for Behavioral Interventions and sits on the Editorial Boards of several other journals.

Rachel N.S. Cavalari, Ph.D., BCBA-D , is a New York Licensed Psychologist and Licensed Behavior Analyst, at the Institute for Child Development at Binghamton University. She is an Adjunct Professor in the Department of Psychology and also serves as Practicum Liaison and Coordinating Instructor for the Undergraduate Psychology Major Track in Applied Behavior Analysis and as the BACB Approved Continuing Education Coordinator. Her current interests include staff training, behavioral assessment and intervention, diagnostic evaluation, systems analysis, and regulation and practice issues for clinicians. Dr. Cavalari received her doctorate in Clinical Psychology from Binghamton University in 2012. Dr. Cavalari served on the Board of Directors for the New York State Association for Behavior Analysis from 2013 to 2014 and has since served on the NYSABA Legislative Committee.

Jennifer M. Gillis, Ph.D., BCBA-D , is an Associate Professor of Psychology and the Associate Director of the Institute for Child Development at Binghamton University. She serves as Co-Director of the Undergraduate Psychology Major Track in Applied Behavior Analysis. Dr. Gillis is an Adjunct Assistant Professor at 
Upstate Medical University. Her professional and research interests include the training of clinicians, behavior analysts, and caregivers, assessment and treatment of autism spectrum disorders, and development and evaluation of systems of data collection and analysis. Dr. Gillis received her doctorate in Clinical Psychology from Binghamton University, after completing her predoctoral internship at Alpert Medical School of Brown University. From 2006 to 2012 she was an Associate Professor in the Psychology Department at Auburn University. Dr. Gillis previously served as the Executive Director for the Alabama Association for Behavior Analysis and continues to remain active in issues related to policy and dissemination.

Ronald Leaf, Ph.D. , is a licensed psychologist who has over 40 years of experience in the field of Autism Spectrum Disorder. He began his career working with Ivar Lovaas while receiving his undergraduate degree at UCLA, subsequently receiving his doctorate under the direction of Dr. Lovaas. During his years at UCLA he served as Clinic Supervisor, Research Psychologist, Interim Director of the Autism Project, and Lecturer. He was extensively involved in several research investigations, contributed to the Me Book, and is a coauthor of the Me Book Videotapes, a series of instructional tapes for teaching autistic children. Dr. Leaf has consulted to families, schools, day programs, and residential facilities on a national and international basis and presently serves as Director of Autism Partnership. Dr. Leaf has published extensively in research journals and is the coauthor of $A$ Work in Progress, Time for School, It Has to Be Said!, Crafting Connections, and A Work in Progress Companion Series.

Sally Rogers, Ph.D. , is a developmental psychologist, clinician, Professor of Psychiatry and Behavioral Sciences, and Director of Training and Mentoring at the MIND Institute, University of California Davis. She has been the principal investigator of several NIH-funded multi-site autism research projects, including a 10-year CPEA program project and two funded Autism Centers of Excellence (ACE) network projects. She has served as president of the International Society for Autism Research, associate editor of the journal Autism Research, a member of the Autism Speaks Global Autism Public Health Initiative, a fellow of the American Psychological Association, Division 33, and a member of the Autism, PDD, and other Developmental Disorders workgroup for the DSM 5. The Early Start Denver Model that she developed with Geri Dawson and other colleagues at the University of Colorado Health Sciences Center, the University of Washington, and the University of California Davis is internationally known and recognized by Time. com and Autism Speaks as one of the ten most important scientific findings of 2012.

Mark Sundberg, Ph.D., BCBA-D , is a licensed psychologist with over 40 years of clinical experience who consults for public and private schools that serve children with autism. He received his doctorate degree in Applied Behavior Analysis from Western Michigan University (1980), under the direction of Dr. Jack Michael. $\mathrm{He}$ is the author of the Verbal Behavior Milestones Assessment and Placement Program (VB-MAPP) and coauthored the ABLLS and the book Teaching Language 
to Children with Autism or Other Developmental Disabilities. He is the founder and past editor of the journal The Analysis of Verbal Behavior, twice past president of The Northern California Association for Behavior Analysis, past chair of the Publication Board of ABAI, and has served on the Board of Directors of the B. F. Skinner Foundation. Dr. Sundberg has given hundreds of national and international conference presentations and taught 80 college and university courses on behavior analysis, verbal behavior, sign language, and child development. In 2013, he received the "Jack Michael Outstanding Contributions in Verbal Behavior Award" from ABAI’s Verbal Behavior Special Interest Group. 



\section{About the Editors}

John McEachin is a behavior analyst and licensed psychologist who has been providing intervention to children with autism as well as adolescents and adults with a wide range of developmental disabilities since 1977. He received his graduate training under Professor Ivar Lovaas at UCLA on the Young Autism Project. During his 11 years at UCLA, Dr. McEachin served in various roles including Clinic Supervisor, Research Assistant, and Teaching Assistant. His research has included the long-term follow-up study of the participants in the Young Autism Project, which was published in 1993. In 1994 he joined with Ron Leaf in forming Autism Partnership, which they co-direct. In 1999 they published A Work in Progress, a widely used behavioral treatment manual and curriculum for children with autism. Dr. McEachin has lectured throughout the world and coauthored numerous books and research articles. He consults regularly to families, agencies, and school districts, assisting in the development of treatment programs and providing training to parents, group home staff, and classroom personnel.

Raymond G. Romanczyk is a SUNY Distinguished Service Professor in the Clinical Psychology program at Binghamton University. He is a NY Licensed Behavior Analyst, NY Licensed Clinical Psychologist, and a Board Certified Behavior Analyst-Doctoral and received his Ph.D. from Rutgers University. In addition, Dr. Romanczyk is an Adjunct Professor of Psychiatry of the SUNY Health Sciences Center of Syracuse. Dr. Romanczyk is the founder and director of the Institute for Child Development that has been providing clinical and educational services to children and families for 40 years, and is one of ten programs cited in the Educating Children with Autism report of the National Research Council.

$\mathrm{He}$ is a Fellow of the American Psychological Association and he is a founding board member of the Association of Professional Behavior Analysts, was a member of the scientific advisory board of the National Autism Center, and a founding board member of the Council on Autism Services, a national organization of directors of autism service agencies. He is a consultant to the NYS Department of Health Early Intervention Program and was a panel member on the NYSDOH clinical guidelines 
for autism, one of the first empirically based reviews of autism assessment and treatment practices. He also serves as an associate editor and member of the editorial board and reviewer for numerous professional journals. Recent published works include "Efficacy of Behavioral Interventions for Young Children with Autism Spectrum Disorders: Public Policy, the Evidence Base, and Implementation Parameters" and "The Status of Treatment for Autism Spectrum Disorders: The Weak Relationship of Science to Interventions." Dr. Romanczyk has presented several hundred addresses at regional, national, and international professional conferences regarding his applied and research work at the Institute and has received numerous awards for his clinical and research accomplishments. 